\title{
Crop-raiding Baboons (Papio anubis) and Defensive Farmers: A West African Perspective
}

\author{
Y. Warren \\ School of Human and Life Sciences, Whitelands College, Roehampton University, Holybourne \\ Avenue, London SW15 4JD \\ (Corresponding address: $\operatorname{Dr} Y$ Warren, Research Coordinator, Takamanda Mone Landscape \\ Project, Wildlife Conservation Society (WCS), Limbe, Cameroon) \\ E-mail: ymkewarren@yahoo.co.uk
}

\begin{abstract}
Baboons are often reported as the worst crop-raiders in Africa, but there has been little observation of the actual behavioural-ecology of their crop-raiding, especially in West Africa. The paper examines the crop-raiding behaviour of a group of habituated baboons (Gamgam group) near the village of Gashaka on the south-western border of Gashaka Gumti National Park, Nigeria. Data were collected during the wet and dry crop seasons via scan sampling and ad libitum techniques. For scan sampling the activity of each observed individual was noted every 2.5 min. For ad libitum data any activity relevant to crop-raiding was noted when it occurred, including the reactions of farmers who were guarding their fields. Descriptive statistics were generated and trends in baboon and human behaviour examined. Sixty-nine percent of Gamgam group's raids were successful. Farmers only prevented or reduced the time baboons spent in fields on $28.9 \%$ of all raids. Crops eaten varied from ripe maize to scavenging for scraps of sweet potato in harvested fields. Maize (ripe and dried) was the most frequently eaten crop. All members of Gamgam group, including weaned infants, ate all crops, but only adult males ate bananas. Observations suggested that baboons used cheek pouches to store food before moving to a safer locality to eat, to avoid farmers' attacks and intragroup competition. Deterrent methods included guarding, fences of fish net, poisoned baits, olfactory, visual and auditory scaring devices. Guarding presence in fields was not regular. In the wet season guards reacted to baboon crop-raiding on 54\% of raids and in the dry season on $44 \%$. On average it took farmers 23 min to react to baboons in their fields. The two most common reactions of guards were shouting and chasing baboons. Observations do not suggest that any one particular defence method can prevent baboon crop-raiding.
\end{abstract}

\section{Introduction}

Humans and primates have been interacting for hundreds of years, in various forms of relationship (Sponsel et al., 2002). Numerous commensal primates crop-raid, and their activity is often the focus of human-wildlife conflict research. Baboons have gained their crop-raiding reputation because of their frequent, year-round foraging on crops, and the apparent impossibility of controlling this activity (Warren, 2003). This is compounded by their large population numbers and wide distribution, resulting in their gaining pest status throughout much of their geographical range.

For baboons, feeding on crops is a good strategy that increases foraging efficiency and nutrient intake (Forthman-Quick \& Demment, 1988; Naughton-Treves, 1998). For farmers, baboons are a problem because of the destruction they cause to every stage of crop growth, and the time and energy required to prevent their raids. Apart from the frequency and wide dispersal of their raiding, baboons are perceived to be worse than other crop-raiding species because of their reportedly strategic raiding and the amount of collateral damage they do to crops (Maples et al., 1976; Naughton-Treves, 1997; Hill, 2000). Baboons are a major source of human-wildlife conflict throughout Africa.

The majority of research has been carried out in East Africa. Only a few studies have actually observed baboons foraging on crops (Maples et al., 1976; Forthman-Quick \& Demment, 1988; Strum, 1994); rather, information has been garnered from farmers' reports, or measuring the damage to crops in fields (Else, 1991; Hill, 1997; Naughton-Treves et al., 1998). Baboons possess all of the attributes that make some animals good crop-raiders: rapid learning ability, opposable thumbs, behavioural, social and dietary flexibility, terrestriality and broad habitat tolerance (Else, 1991; Gautier \& Biquand, 1994). By incorporating feeding on crops into their foraging strategies baboons have somewhat transformed their activity budgets (Forthman-Quick, 1986). Social 
organisation may also be affected by foraging on crops (Dunbar \& Dunbar, 1974; Maples et al., 1976; Strum, 1994).

Some studies have found a regular temporal and spatial patterning of baboon foraging on crops (Maples et al., 1976; Else, 1991; Naughton-Treves, 1998; Naughton-Treves et al., 1998; Hill, 2000), but others have not (Maples et al., 1976; Else, 1991; Naughton-Treves, 1998; NaughtonTreves et al., 1998; Hill, 2000). Specific behaviours have been reported for baboons when they forage on crops, such as increased vigilance, reduced vocalizations, rapid foraging and carriage of food away from fields in cheek-pouches (Maples et al., 1976; Forthman-Quick \& Demment, 1988; Else, 1991).

The paper explores the behaviour and dynamics of an habituated group of baboons (Papio anubis) when they forage on crops in agricultural areas near the village of Gashaka, on the southwestern border of Gashaka Gumti National Park, Nigeria. As well as analysing some factors that have not been reported for baboon crop-raiding activities, like the reactions of farmers, the paper interprets baboon crop-raiding in the light of observations on Gamgam group, and over 30 years of observations of wild-foraging baboons. The obective is to provide a more detailed understanding of the dynamics of crop-raiding using the Gashaka site as a case study and as a basis for further research into the behavioural-ecology of crop-raiding by baboons.

\section{Materials and methods}

Observations were on a group of habituated crop-raiding baboons (Gamgam group). Modal group size during the study was 14, including four adult males, four adult females, three juveniles and three infants. The baboon population of the park adjacent to the study group's range has been estimated between 120,000-200,000 (Dunn, 1998). Farmers were of mixed age, sex, and ethnicity.

Study site

The baboons foraged on crops in fields about $1 \mathrm{~km}$ from the south-western boundary of Gashaka Gumti National Park (GGNP), Nigeria. The study group's home range was $1.5 \mathrm{~km}^{2}$ and up to 3\% of the area contained crops depending on the season. The baboons foraged on crops belonging to subsistence farmers of Gashaka village. A wet season maize crop was planted in April/May 2001 and harvested in August/September 2001, and a dry season maize crop was planted in November/December 2001 and harvested in March 2002. There was one cassava and three sweet potato fields in the agricultural area within the group's range in the 2002 dry season; these fields were no more than $150 \mathrm{~m}^{2}$ in total.

Cassava and sweet potatoes are annual crops, but may be left in the ground until needed. Cassava is planted in April and sweet potato in June. All crops were planted as single stands. There were also scattered banana and palm trees around the maize fields. As people do not live near the fields there were no areas where Gamgam group could forage on human rubbish. The majority of Gamgam group's home range was southern Guinea savanna woodland, with elephant grass, gallery and lowland forests in smaller areas. Annual rainfall was $1,875 \mathrm{~mm}$, in the year of study, falling between May and October. Mean monthly tempera-ture was $26.9{ }^{\circ} \mathrm{C}( \pm 6.6)$.

\section{Data collection}

Gamgam group was followed for 8 days each month, for $10 \mathrm{~h}$ a day, with early (06:00 h) and late starts $(08: 00 \mathrm{~h})$ on alternate days. Data were collected using a Psion ${ }^{\mathrm{TM}}$ workabout handheld computer and Observer ${ }^{\mathrm{TM}}$ software (Noldus Information Technology, 1996). Behavioural observations were collected via group scan samples at 2.5 min intervals (Altmann, 1974). The baboons' actions when foraging on crops were recorded continuously. When following baboons into agricultural areas ad libitum observations of farmers' behaviour were also recorded. For each foray into a field a record was made of the attempt, the outcome of the attempt and farmers' reactions. Group size, location and habitat were recorded every half hour.

The baboons' actions when foraging on crops are termed raiding. Raids were defined in several ways depending on their outcome (Table 1). All entrances into one agricultural area within any $1 \mathrm{~h}$, 
whether foraging on one type of crop or more, were counted as one attempted raid. If Gamgam group was chased away by farmers or voluntarily left fields, but (i) returned to the same field within an hour, this was counted as a single attempted raid, (ii) returned to the same field after one hour or more, this was counted as two attempted raids, or (iii) moved on to raid in a different agricultural area, this was counted as two attempted raids. The time limit of $1 \mathrm{~h}$ was selected because several observations suggested that baboons would attempt raids several times within an hour, then move on to forage elsewhere.

TABLE 1

The number of attempted and successful crop-raids by a group of baboons from Gashaka Gumti National Park, Nigeria

Description

Attempted raid: Any observations of baboons moving towards crop fields within $50 \mathrm{~m}$ of overlooking crop fields, or of baboons in fields foraging on crops, or leaving fields with crops. agricultural areas, or in prominent positions

Number of observations of raids Percent of Wet season Dryseason Total attempted raids

$13 \quad 32 \quad 45$

Outcome of attempted raids

\section{Unsuccessful}

Thwarted: Attempted raids prevented by farmers' shouting, stoning or chasing baboons before they entered the fields.

Unknown: Outcome of attempted raids could not be determined, for example if the group was lost.

Prior self-termination: Baboons terminated attempted raids prior to entering fields.

\section{Successful}

Successful: When baboons were seen foraging in fields or moving away from fields carrying crops in the mouth, hands or cheek pouches.

Self-terminated: When baboons left fields without any obvious active human intervention.

Unknown: Outcome of successful raids could not be determined.

Interrupted: Baboons were successfully foraging in fields but were chased off by farmers.

$$
2
$$

3

0

8

4

1

3
2

1

6

23

12

5

6
4

4

6

31

16

6

9
8.9

8.9

13.3

68.9

51.6

19.4

29

\section{Data analysis}

Data from months when crops were available in fields (June-August 2001 and November 2001March 2002) (Table 2), totalling 549 h, were analysed. Forty-five attempted raids, including those on maize stores and fields that had been harvested, but in which baboons foraged, were also included in raid analyses. Stores are not actively guarded, but they are close to fields, and farmers chase the baboons if they see them nearby. Results were examined for trends in baboon and human behaviour. Descriptive statistics were produced, and frequencies of parameters were the unit of analysis. Null hypotheses were examined using the Chi-squared test. The level of significance was taken at $P<0.05$. All investigation was undertaken using Excel 2003.

TABLE 2

The number of successful raids on different crop types and the percentage of total observations in months when crops were available in fields. Shaded cells indicate when each crop type was available

West African Journal of Applied Ecology, vol. 14, 2008 


\begin{tabular}{|c|c|c|c|c|c|c|c|c|}
\hline Crop & Jun 01 & Jul 01 & Aug 01 & Dec 01 & Jan 02 & Feb 02 & Mar 02 & Total \% \\
\hline Fresh maize & & 7 & 3 & & & 6 & 7 & 42.6 \\
\hline Stored maize & & & & 1 & 3 & 3 & & 13.0 \\
\hline Harvested cassava & & & & & 3 & 4 & & 13.0 \\
\hline Harvested sweet potato & & & & & 3 & & 3 & 11.1 \\
\hline Banana* & & & & & 1 & & 3 & 7.4 \\
\hline Fresh sweet potato & & & & 2 & & & & 3.7 \\
\hline Harvested maize & & & & & & & 2 & 3.7 \\
\hline Maize stems & 1 & & & & & & & 1.9 \\
\hline Fresh cassava & & & & 1 & & & & 1.9 \\
\hline Green leaf & & & & & & 1 & & 1.9 \\
\hline
\end{tabular}

*Only adult males were observed to eat bananas.

\section{Dynamics of raiding}

\section{Results}

The Gashaka farmers' techniques for deterring baboons and other animals from raiding fields are presented first to put the results into context. Some of the data are qualitative due to the difficulty of observing several subjects at one time. The deterrent methods included guarding, lighting fires, fences of fish net, scarecrows, auditory scaring devices, snares and poisoned baits. Guarding generally consisted of farmers sitting in huts near fields, or performing farming duties, such as weeding. Guards would shout, chase, throw spears, or use slingshots to repel the baboons. Some guards were present on their farms from dawn to dusk, others more sporadically during the day. In the wet season guards reacted to baboon crop-raiding on $54 \%$ of raids $(\mathrm{N}=13)$ and in the dry season on $44 \%(\mathrm{~N}=32)$. It is assumed that when there was no reaction this was due to the absence of guards, however, there were two occasions when guards were present and did not react. Dense vegetation meant farmers were not always visible even when present, only twice could it be confirmed that guards were not present.

The most common reaction was to shout at crop-raiding baboons ( $47 \%$ of farmer reactions). This was sometimes combined with using a sling shot (24\% of farmer reactions) or stones were hurled at baboons without shouting (19\%). Baboons were never seen to be hit by stones. The baboons were also chased (38\% of farmer reactions), although only once for more than $100 \mathrm{~m}$. Baboons tended to stop running on reaching a refuge.

It was reported that snares are used to trap baboons and they are then killed with a spear. In December 2001, one adult male in Gamgam group was observed limping and the features of a wound around the ankle suggested that it might have been due to a snare. The animal recovered from the injury. The number, spatial distribution and location of passive prevention techniques, such as scaring devices, changed seasonally and sometimes within a season due to lack of maintenance, or decisions by farmers. Traditional plant poisons, Gamalin 20 and battery acid were reported to be used as poisons. Poisoned fruit baits occurred sporadically with only two suspected incidences. Baboons were seen to walk past poisoned pawpaw and snares, circumvent netting, and raid fields from the opposite end to which guards were standing. Gamgam group was seen to scout the edges of fields picking off maize cobs whilst being harassed by farmers.

A total of 45 attempted raids were observed, $68.9 \%$ were successful. The majority of raids were terminated by the baboons themselves (51.6\%) and less than a third of raids were interrupted by farmers (Table 1). Attempted and successful raids occurred at a rate of 0.08 per hour of observation. Farmers only prevented four of the 45 attempted raids. Ten $(32.3 \%, \mathrm{~N}=31)$ were successful despite attempts by farmers to repel the baboons prior to their entering a particular field, or when they were already foraging in fields. Even when farmers chased baboons away before they had entered fields this did not necessarily mean the entire group was unsuccessful, as some individuals could have entered the fields unobserved. The mean time of farmers' reactions to baboons' presence near fields prior to their entering fields was $23 \min (\mathrm{N}=8)$. Once baboons were in fields the mean time to reaction of farmers was also 23 min $(\mathrm{N}=6)$. If baboons were thwarted from entering a field they 
tended to raid other fields within the vicinity. For three attempted raids this occurred within an hour of their first attempted raid. On other attempts they raided other fields later the same day. If unsuccessful, Gamgam group was not observed to return to the same field the same day.

\section{Behaviour during raiding}

The ranging patterns of Gamgam group revealed they spent the least proportion of location records actually in fields (Fig. 1). This difference was significantly less than expected given the size of the area of fields within their home range (based on an expected proportion of location records in relation to size of each habitat type within the home range; $\chi^{2}=719.9$, $\mathrm{df}=4, P<0.001$ ). From all of the location records collected every half-hour $(\mathrm{N}=797), 10 \%$ were within $50 \mathrm{~m}$ and in fields, and $26 \%$ were within $100 \mathrm{~m}$ and in fields. Time spent near fields was not significantly greater than time spent ranging elsewhere (time spent within $50 \mathrm{~m}$ compared to time elsewhere $\chi^{2}=243.971$ and time spent within $100 \mathrm{~m}$ compared to elsewhere $\chi^{2}=119.185$, with $\mathrm{df}=1, P>0.001$ in both cases). However, the shape of Gamgam group's home range and the location of fields within it meant that the group was never more than $700 \mathrm{~m}$ from fields at any one time.

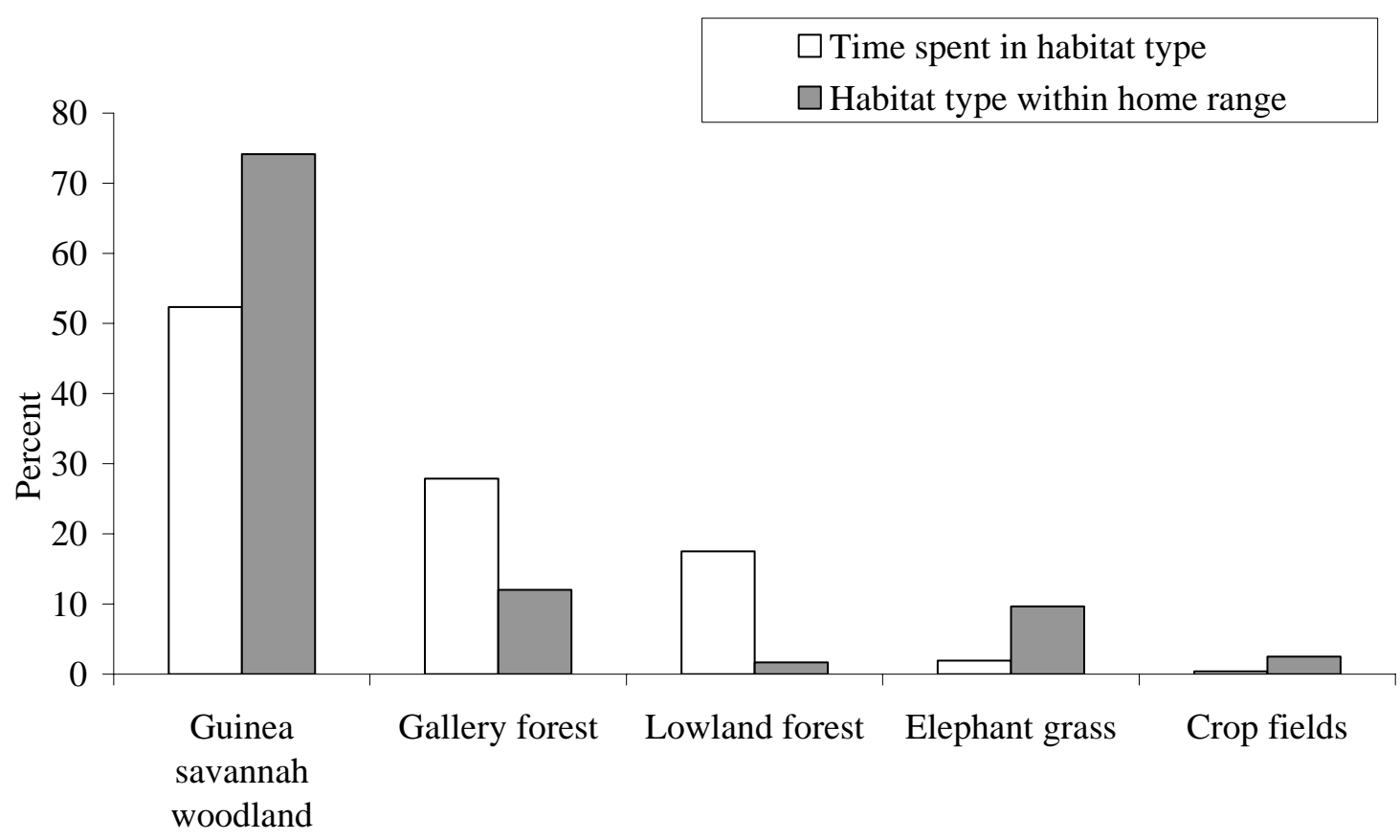

Fig. 1. The percent of time a group of crop-raiding baboons spent within different habitats within their home range compared to the percentage habitat composition of the home range.

The time baboons spent in fields varied according to the crop being raided and farmers' actions. When foraging on underground crops long periods were spent in fields digging up cassava and/or sweet potatoes (mean 55 min, $\mathrm{N}=10$ ). Lengthy periods were also spent foraging on maize from stores (mean 65 min, $\mathrm{N}=5$ ). Reduced visibility meant that it was impossible to time precisely the duration of Gamgam group's foraging forays into maize fields, but typically the baboons spent enough time to pick one or two cobs and then return to a refuge to eat. When foraging on crops Gamgam group was highly vigilant and on occasion took up a bipedal stance. The group was never noted to vocalize loudly when approaching or in agricultural areas and tended only to bark when farmers shouted at them or shot stones at them using sling shots. In the dry season, adult and subadult animals of Gamgam group were observed to wade across a river nine times to forage on maize. Infants and small juveniles were never observed to cross the river and the group was not observed wading through water at any other time. 
A clearly defined vigilance behaviour (elevated pre-vigilance) took place prior to entering fields, with baboons sitting in elevated positions within $50 \mathrm{~m}$ of agricultural areas looking in the direction of fields. All members of Gamgam group engaged in elevated pre-vigilance behaviour. This elevated pre-vigilance was observed during 62\% of all Gamgam groups' attempted raids, 38\% of all raids in which pre-vigilance took place were successful. There was a significant difference in whether a raid was (i) successful, (ii) thwarted, (iii) self-terminated, or (iv) unknown outcome (Table 1$)$, when elevated pre-vigilance occurred $\left(\chi^{2}=17.857, \mathrm{df}=3, P<0.001\right)$.

\section{Crops eaten}

The total number of different crops eaten was recorded for each successful raid (Table 2). There were 54 observations of Gamgam group foraging on one, or other, of a variety of crops, including growing maize and scraps of sweet potato left in harvested fields. This figure exceeds the total number of raids as in any one entry into agricultural areas more than one type of crop could be eaten.

\section{Temporal aspects}

The daily and annual timing of raids was investigated. Peaks in maize raiding occurred just prior to harvesting of the ripe maize in July/August 2001 and February/March 2002 (Fig. 2). The peak in raiding in March 2002 was the result of baboons foraging on bananas, and scavenging in harvested maize and sweet potato fields. There was a significant difference between months in the number of attempted raids $\left(\chi^{2}=237.695, \mathrm{df}=6, P<0.01\right)$.

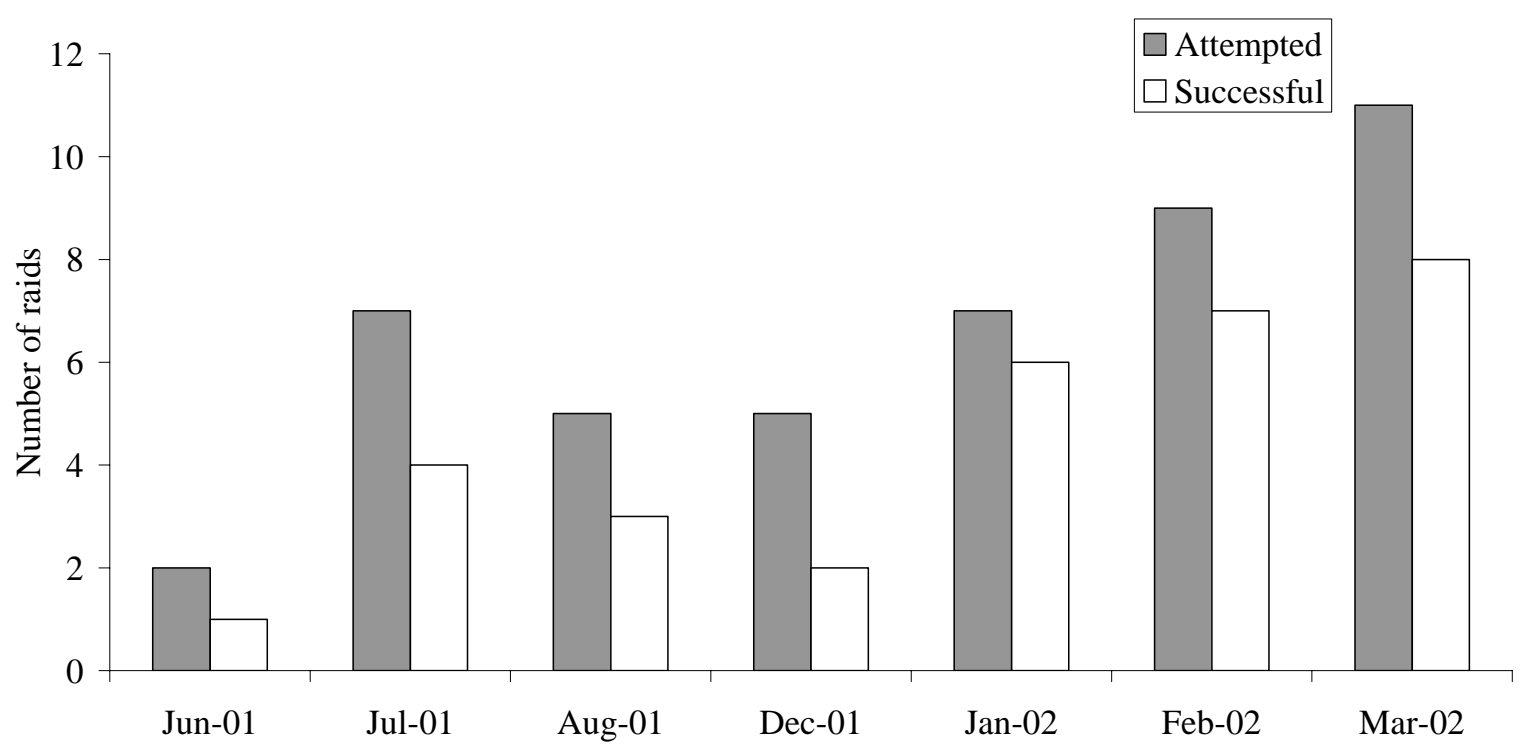

Fig. 2. The number of attempted and successful crop raids per month by a group of crop-raiding baboons in months when crops were available in fields (see Table 1 for definitions).

The number of attempted and successful raids occurring in any $1 \mathrm{~h}$ peaked between 12:00 and 13:00 h (Fig. 3). However, there was no significant difference in the number of raids per hour $\left(\chi^{2}=\right.$ 11.365, $\mathrm{df}=12, P>0.05)$. 


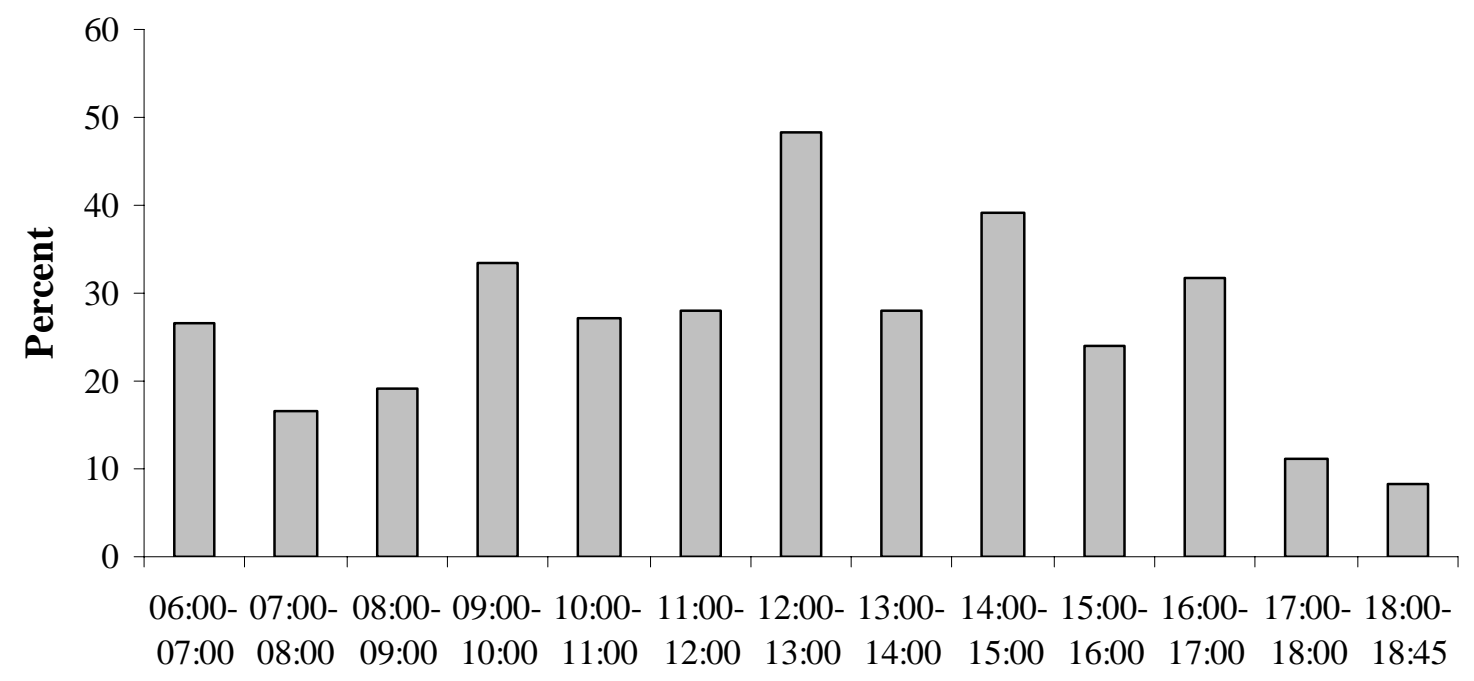

Hour of day

Fig. 3. Daily pattern of crop-raiding by a group of baboons (percent of hours in which attempted or successful raids were observed as a proportion of the total number of times observations were made in an hour on raid days).

Cheek pouch use

Gamgam group members were frequently seen leaving fields with bulging cheek pouches and moving to 'safer' locations to feed. Safer areas included refuges where farmers did not enter (e.g. elephant grass) or elevated positions from which baboons could observe farmers approaching. Generally, such refuges were less than $50 \mathrm{~m}$ from fields. Cheek pouch use made up a small proportion of the total time baboons spent foraging (11.3\% of observations of foraging on identified items). However, significantly more time was spent using cheek pouches when crop-raiding (17.7\% of all crop foraging, $\mathrm{N}=1038$ scans of foraging on identified foods) compared to non-raiding situations ( $10.0 \%$ of all non-crop foraging, $\mathrm{N}=5228, \chi^{2}=1890.766$, $\left.\mathrm{df}=1, P<0.001\right)$. Gamgam group was also observed to carry food away from fields in the hand, or mouth.

Cheek pouch use may be a means of avoiding aggression from other animals when foraging. Aggressive incidents $(\mathrm{N}=49)$ were more common when Gamgam group was foraging on crops (18.4\%) compared to foraging at other times $(8.2 \%)$ but this difference was not significant $\left(\chi^{2}=\right.$ 1.923 , df $=1, P>0.05)$. Overall aggression was greatest during rest periods $(40.8 \%)$. For the purposes of this analysis activity periods were designated according to major group activity across the 2.5 min scan before and after the aggressive incident scan.

\section{Social aspects}

Gamgam group's social group size was smaller (mode 14 individuals), than GGNP baboon groups in general ( $20 \pm 6, \mathrm{~N}=15$, and $22 \pm 4, \mathrm{~N}=7$; mean for groups with and without access to crops, respectively) (Higham, 2006). There were two groups that had overlapping ranges with Gamgam group and raided the same fields. These contained around 37 and 26 individuals (S. Waziri, pers. com. 1999, and B. Bello, pers. com. 2000).

The number of individuals that raided, henceforth called 'raiding party', was sometimes difficult to assess. When raiding cassava or sweet potato, the whole of Gamgam group could be seen in the fields, but when raiding maize, visibility was severely restricted and only some group members could be seen. Mean raiding party size was six ( \pm 4 , range 1-14) when assessed from the total number of different individuals that were seen in an attempted or successful raid. This suggests raiding party size is smaller than social group size. The raiding party size of Gamgam group's neighbours was not observed, but Gashaka farmers never reported large groups raiding their fields.

The composition of raiding parties was variable. All members of Gamgam group crop-raided including a female carrying her infant ventrally. A typical raiding party consisted of two adult West African Journal of Applied Ecology, vol. 14, 2008 
males, two adult females, one juvenile and three infants. Adult males took part in $88.9 \%$ of all raids, adult females in $71.1 \%$, juveniles in $71.1 \%$ and infants in $48.9 \%$, but the difference in the number of raids that each age-sex class took part was not significant when adjusted for group agesex composition $\left(\chi^{2}=8.493\right.$, df $\left.=3, P>0.05\right)$. There did not appear to be any systematic way in which the social group split when raiding, merely some members entered fields whilst others remained in nearby areas, 'watching', resting, foraging on other foods, or continuing to travel. Individuals would also come and go during a raid, particularly when foraging on underground crops. Some members would remain in the field eating whilst others carried food to the forest to eat.

\section{Dynamics of raiding}

\section{Discussion}

It was difficult to gain much information on the success of techniques used to prevent baboon cropraiding, as some were not legal and people were not willing to discuss them. The attempts made by Gashaka farmers to prevent crop-raiding baboons were on the whole ineffective, merely reducing the severity of damage. In Africa, extensive extermination programmes against baboons do not seem to have greatly impacted on their crop-raiding activities. Thus, despite human actions, baboons remain successful crop-raiders throughout their range.

Gashaka baboons and those elsewhere can adjust their behaviour and flight distances to the hazards of the raiding situation (e.g. Biquand et al., 1994). On at least two occasions when Gamgam group was rebuffed by guards the group re-initiated raiding (within $1 \mathrm{~h}$. of the first attempt) in the same field from the opposite direction from which they had been rebuffed. Examples of apparently 'sneaky' behaviour have previously been reported for crop-raiding baboons (e.g. Maples et al., 1976; Naughton-Treves, 1997). It is suggested that primates are successful raiders because of their intelligence (Else, 1991). Investigation of 'Machiavellian Intelligence' in primates (Byrne \& Whiten, 1989) reveals that baboons could have the cognitive ability to be very perceptive in their reactions to guards. However, examples of 'tactical deception' (when one part of a group raids whilst another distracts the farmer) (Lee \& Priston, 2005) could merely be a result of the way in which baboon groups divide when foraging (pers. obs.).

A question that arises from the study, and one in Bali, where farmers detected long-tailed macaques (Macaca fascicularis) on average after $32 \mathrm{~min}$ ( $\mathrm{N}=8$ days; Wheatley, 1999), is why does it take farmers so long to detect crop-raiding primates? The study suggests reduced vocalizations may be a strategy of primates to avoid detection, but this requires quantitative confirmation via further research. Alternatively, the time to reaction presumably depends on the motivation of individual farmers and the influences on this could be manifold. Of particular importance would be the value of the crop to the individual, but the extent of damage by baboons, age, sex, gender and other socioeconomic factors could also come into play.

\section{Behaviour during raiding}

It is probable that because of their crop-raiding activities baboons view humans as predators (Else, 1991). According to predation theory it would be predicted that baboons should move quickly through fields, eat only small items, or carry food away with them (Hill \& Dunbar, 1988). This is indeed what the Gamgam baboons did. Yet they concentrated their general ranging behaviour in the vicinity of agricultural areas. Similar concentration of range use by other provisioned primates has been noted (e.g. Barbary macaques; Fa, 1986) and food availability is generally an important ecological variable in primate ranging behaviour (Gottfried et al., 2006). Therefore, a ranging pattern concentrated near a high-quality food source is likely a behavioural ecological pre-adaptation to crop-raiding.

The rate of raiding observed for Gamgam group (0.08 per hour of observation) was very low compared to the 1.8 raids per hour of observation for crop-raiding yellow baboons studied by Maples et al. (1976) in Kenya. It is unlikely that variation in definitions of a 'raid' could account for the major difference in raiding frequency between these East and West African studies. Rather, the variation could be explained by the larger size of the Kenyan group and the greater area of crops. 
The adoption by the Gashaka baboons of a specific vigilance behaviour (elevated pre-vigilance) when crop-raiding might be a modification of behaviour to increase the success of raiding, or reduce the level of predation by humans. Similar reports of specific vigilance behaviours when crop-raiding have been reported for baboons (Maples, et al., 1976; Naughton-Treves, 1997). The behaviour seems unlikely to have evolved expressly for crop-raiding, but may be a pre-adaptation, as 'scanning' for various reasons, such as observing for the presence and location of own and nongroup conspecifics, or predators, has been recorded amongst baboons (Altmann \& Altmann, 1970; Hamilton \& Bulger, 1992). Increased vigilance might occur for other reasons, e.g. in males as a reproductive strategy (Cowlishaw, 1998), but it seems unlikely to account for this heightened vigilance just before raiding.

\section{Crops eaten}

Baboons have been recorded eating a wide variety of crops, but it seems that a high level of maize consumption is widespread (Forthman-Quick \& Demment, 1988; Else, 1991; NaughtonTreves et al. 1998; Hill, 2000). Scavenging maize from harvested fields, as seen in Gashaka, has only once been previously reported from Roka, Kenya (Greenhood, 1971). Availability of crops, nutritional differences and harvesting rates could explain what appears to be a general preference for maize by baboons.

\section{Temporal aspects}

Raiding when ripe crops are available (Else, 1991; Naughton-Treves, 1998; Hill, 2000) is likely part of an optimal foraging strategy. Crop-raiding primates have been noted to have temporal raiding patterns (Forthman-Quick, 1986; Else, 1991). Yet others have reported the unpredictable nature of the time of day baboons' crop-raid (e.g. Biquand et al., 1992). Farmers in GGNP generally reported that baboons raided when people were absent (unpublished data), and it was thought that Gamgam group would opportunistically forage in fields when farmers were absent. Although there was a peak in crop-raiding when farmers may have been absent at lunch times this was not statistically significant, and almost half of all crop-raids were carried out when farmers were present. This suggests that by guarding, farmers may reduce, but not necessarily prevent damage to their crops.

\section{Use of cheek pouches}

The use of cheek pouches and aggression amongst Gamgam group was found to be greater when foraging on crops than when foraging in non-crop-raiding situations. This supports hypotheses that the use of cheek pouches by primates is a means of avoiding intragroup competition (Lambert \& Whitham, 2001). When primates forage on highly valued foods, such as crops, there may be increased competition (Lee, 1988). In addition, this concurs with the hypothesis that use of cheek pouches allows animals to gather foods rapidly and move to protective cover to avoid predation (Murray, 1975). Thus, Gamgam group uses cheek pouches during foraging on crops to avoid farmers and competition between individuals. Cheek pouches are evidently a pre-adaptation well suited for crop-raiding.

\section{Social aspects}

Smaller groups may be less conspicuous to guards and, therefore, an advantage when cropraiding (Forthman-Quick, 1986). This applies to overall social group size and the size of the raiding party. The social group size of baboons which gain all or part of their diet from human sources has been found to be larger (Samuels \& Altmann, 1991) and smaller (Else, 1991; Biquand et al., 1994) than wild foraging baboons at the same study sites. Mean Gamgam group size from half-hourly records collected from May 2001 to April 2002 was also smaller than social group size $(4 \pm 2, \mathrm{~N}=$ 504). It seems unlikely that the small size of Gamgam group was the result of a modification of social group size to avoid detection when crop-raiding. Fissioning has been observed in other baboon populations (Aldrich-Blake et al., 1971; Dunbar \& Nathan, 1972). It was reported that previously members of Gamgam group were seen raiding with a larger group. This suggests that Gamgam group members may have recently split from the larger group. Stoning and chasing 
caused fissioning of rhesus macaque raiding groups (Southwick \& Siddiqi, 1994). Similarly, harassment by farmers might be a factor in Gamgam group’s small social group and raiding party size.

Previous researchers have described baboons splitting into smaller groups to raid (e.g. Maples, 1969). In contrast, farmers around Budongo Forest Reserve, Uganda report olive baboons raiding farms in large groups (Hill, 2000), and farmers surveyed in GGNP reported that baboons came to their fields in large groups (Warren, 2003). Raiding party size might be flexible depending on individual motivation, group dynamics, the type of crop being raided and the guarding strategy.

\section{Acknowledgement}

The research was funded by the University of Surrey Roehampton (UK) and took place at the Gashaka Primate Project (GPP), Nigeria), which has received funding from the North of England Zoological Society and the Leakey Foundation. Further financial assistance was from PSBG, NUMICO Research B.V., BFWG and IFAW. Support for the research was given by WWF (UK), the National Parks Service and NCF (Nigeria). The author is grateful to V. Sommer, C. Ross and A. MacLarnon. Thanks to K. Hill, M. McLennan and four anonymous reviewers for comments on an earlier version of the manuscript.

\section{References}

Aldrich-Blake F., Bunn T., Dunbar R. and Headley P. (1971). Observations on baboons, Papio anubis, in an arid region in Ethiopia. Folia Primatol. 15: 1-35.

Altmann J. (1974) Observational study of behaviour: sampling methods. Behaviour. 49: 227-267.

Altmann S. A. and Altmann, J. (1970). Baboon Ecology: African Field Research. University of Chicago Press, Chicago.

Biquand S., Biquand-Guyot V., Boug A. and Gautier J.-P. (1992). The distribution of Papio hamadryas in Saudi Arabia: Ecological correlates and human influence. Int. J. Primatol. 13: 223-243.

Biquand S., Boug A., Biquand-Guyot V. and Gautier J. (1994). Management of Commensal baboons in Saudi-Arabia. Rev. Ecol.-Terre Vie 49(3): 213-222.

Byrne R. and Whiten, A., eds. (1989). Machiavellian Intelligence: Social Expertise and the Evolution of Intellect in Monkeys, Apes, and Humans. Clarendon Press, Oxford.

Cowlishaw G. (1998). The role of vigilance in the survival and reproductive strategies of desert baboons. Behav. 135: 431-452.

Dunbar R. I. M. and Dunbar, P. (1974). Ecological relations and niche separation between sympatric terrestrial primates in Ethiopia. Folia Primatol. 21: 36-61.

Dunbar R. I. M. and Nathan M. F. (1972). Social organisation of Guinea baboon. Folia Primatol. 17: 321-334.

Dunn A. (1998). Gashaka Gumti National Park: A Management Plan for Developing the Park and its Support Zone (Unpublished draft). Nigerian National Parks Service, Nigerian Conservation Foundation, World Wide Fund for Nature, London, UK.

Else J. G. (1991). Non-human Primates as Pests. In Primate Responses to Environmental Change. (H. O. Box, ed.), pp. 155-156. Chapman and Hall, London.

Fa J. E. (1986). Use of time and resources by provisioned troops of monkeys: Social behaviour, time and energy in Barbary macaques (Macaca sylvanus) at Gibraltar. Karger, Basel.

Forthman-Quick D. L. (1986). Activity budgets and the consumption of human foods in two troops of baboons (Papio anubis) at Gilgil, Kenya. In Primate Ecology and Conservation. (J. G. Else and P. C. Lee, ed.), pp. 221-228. Cambridge University Press, New York.

Forthman-Quick D. L. and Demment D. (1988). Dynamics of Exploitation: Differential Energetic Adaptations of Two Troops of Baboons to Recent Human Contact. In Ecology and Behaviour of Food-Enhanced Primate Groups. (J. E. Fa and C. H. Southwick, ed.), pp. 25-51. Alan R. Liss, Inc., New York.

Gautier J.-P. and Biquand S. (1994). Primate commensalism. Rev. Ecol.-Terre Vie 49: 210-212.

Gottfried H., Robbins M. and Boesch C. (ed.) (2006). Feeding Ecology in Apes and Other Primates: Ecological, physical and behavioural aspects. Cambridge University Press, Cambridge.

Greenhood W. F. (1971). Diets and ecology of crop-raiding baboons. In Anthropology. University of Florida, Gainesville, Fl.

Hamilton W. and Bulger J. (1992). Facultative expression of behavioral differences between one-male and multimale savanna baboon groups. Am. J. Primatol. 28: 61-71.

Higham J. (2006). The reproductive ecology of female olive baboons (Papio hamadryas anubis) at Gashaka-Gumti National Park, Nigeria. In School of Human and Life Science. p. 281. Roehampton University, London.

Hill C. M. (2000). Conflict of interest between people and baboons: crop raiding in Uganda. Am. J. Primatol. 21(2): 299314.

Hill C. M. (1997). Crop-raiding by wild vertebrates: The farmer's perspective in an agricultural community in western Uganda. Int.J. Pest Mgmt 43: 77-84. 
Hill R. A. and Dunbar R. I. M. (1988). An evaluation of the roles of predation rate and predation risk as selective pressures on primate grouping behaviour. Behaviour 135: 411-430.

Lambert J. and Whitham J. (2001). Cheek pouch use in Papio cynocephalus. Folia Primatol. 72(2): 89-91.

Lee P. (1988). Ecological Constraints and Opportunities: Interactions, Relationships, and Social Organization of Primates. In Ecology and Behavior of Food Enhanced Primate Groups. (J. E. Fa and C. H. Southwick, ed.), pp. 297311. Alan R. Liss, Inc., New York.

Lee P. and Priston N. (2005). Human Attitudes to Primates: Perceptions of Pests, Conflict and Consequences for Conservation. In Commensalism and Conflict: The Primate-Human Interface.(J. Paterson and J. Wallis, ed.), pp. 1-23. Hignell Printing, Winniipeg, Manitoba.

Maples W. (1969). Adaptive behavior of baboons. Am. J. Phys. Anthropol. 31: 107-110.

Maples W., Maples M., Greenwood W. and Walek M. (1976). Adaptations of crop-raiding baboons in Kenya. Am. J. phys. Anthrop. 45: 309-316.

Murray P. (1975). The role of cheek pouches in cercopithecine monkey adaptive strategy. In Primate Functional Morphology and Evolution. (R. H. Tuttle, ed.), pp. 151-194.Mouton Publishers, Hague.

Naughton-Treves L. (1997). Farming the Forest Edge: Vulnerable People and Places Around Kibale National Park, Uganda. Geogr. Rev. 87: 465-488.

Naughton-Treves L. (1998) Predicting patterns of crop damage by wildlife around Kibale National Park, Uganda. Cons. Biol. 12: 156-168.

Naughton-Treves L., Treves A., Chapman A. C. and Wrangham R. (1998). Temporal patterns of crop-raiding by primates: linking food availability in croplands and adjacent forest. J. appl. Ecol. 35: 596-606.

Noldus Information Technology N. I. (1996). The Observer system for collection and analysis of data. Reference Manual (Version 3.0). Noldus Information Technology, Wageningen.

Samuels A. and Altmann J. (1991). Baboons of the Amboseli basin: Demographic stability and change. Int. J. Primatol. 12: 1-9.

Southwick C. H. and Siddiqi M. F. (1994). Primate commensalism: The Rhesus monkey in India. Rev. Ecol.-Terre Vie 49: 223-231.

Sponsel L. E., Ruttanadakul N. and Natadecha-Sponsel P. (2002). Monkey business? The conservation implications of macaque ethnoprima-tology in southern Thailand. In Primates Face to Face. (A. Fuentes and L. D. Wolfe, ed.), pp. 288-309. Cambridge University Press, Cambridge.

Strum S. C. (1994) Prospects for management of primate pests. Rev. Ecol.-Terre Vie 49(3): 295-306.

Warren Y. (2003) Olive Baboons (Papio cynocephalus anubis): Behaviour, Ecology And Human Conflict in Gashaka Gumti National Park, Nigeria. In Centre for Research into Evolutionary Anthropology. Roehampton University of Surrey, London.

Wheatley B. (1999) The Sacred Monkeys of Bali. Prospect Heights, Waveland Press, Illinois. 